\title{
Skin Penetration of Two Topical Formulations of Gossypol, an Ex vivo Comparative Study
}

\author{
M. CLENT AND L. TENG*
}

School of Pharmaceutical Science, Jiangnan University, Jiangsu Province, P. R. China

\section{Clément and Tang: Comparison of Two Topical Formulations of Gossypol}

\begin{abstract}
Gossypol is a product known for its several biological activities but not usable in clinic due to its toxicity once administered by oral or parenteral route. Two topical formulations of gossypol (L-ascorbyl palmitate and L-ascorbyl ibuprofenate coagels) have been developed to reduce these side effects. In the present study penetration of gossypol entrapped in these coagels at the amount of $5 \% \mathrm{w} / \mathrm{w}$ through the stratum corneum was evaluated. Both coagels were applied on porcine ears separately; 20 tape strips were removed from the same treated area and analysed using a colorimetric method (ferric chloride test for phenol). It was found that gossypol remained distributed within the stratum corneum, thus limiting its availability in systemic circulation where it can cause serious side effects. Hence, gossypol coagel $5 \%$ could be used to target the drug to stratum corneum.
\end{abstract}

Key words: Coagel, gossypol, porcine ears, stratum corneum, toxicity

There has been a surge of interest in gossypol since it has demonstrable therapeutic potential both in vivo and in vitro ${ }^{[1]}$. Gossypol is a naturally occurring lipid soluble polyphenolic constituent (fig. 1) extracted from the cotton plant (Gossypium); it contains polar groups (six hydroxy and two aldehyde groups) making it soluble in most organic solvents ${ }^{[2]}$. It is chemically reactive due to the carbonyl and phenolic hydroxyl groups as well as its bulky binaphthalene structure ${ }^{[3]}$. Therefore, it exerts several biological activities such as antimicrobial activity, essentially against Staphylococcus aureus, Sarcina lutea, Escherichia coli, Candida utilis and Saccharomyces cerevisiae ${ }^{[4]}$; antiretroviral activities such as antiHIV-1 ${ }^{[5,6]}$, inhibitory effect on some arboviruses including sindbis virus, west Nile fever virus, Japanese encephalitis virus, and the virus causing tick-borne encephalitis ${ }^{[7]}$; furthermore, it has stopped influenza, parinfluenza- $3^{[8]}$,

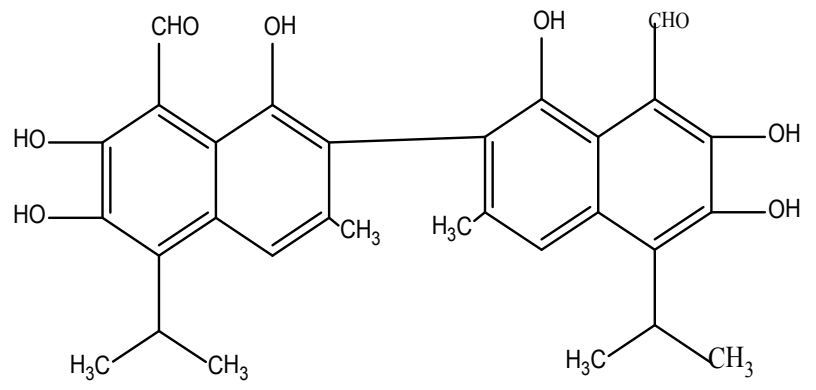

Fig. 1: Chemical structure of gossypol and also herpes simplex virus ${ }^{[9]}$. In addition, it is reported to exert anticancer, antifertility, antiparasitic and antiprotozoan activities ${ }^{[3]}$. Unfortunately its toxicity limits its use in clinic once administered orally or parenterally; it complexes with iron of hemoglobin, which leads to anaemia with reduced numbers of red blood cells and increases its fragility, decreases oxygen release from oxyhemoglobin, and reduces oxygencarrying capacity of blood with lowered hemoglobin and packed cell volume results in shortness of breath, edema of the lungs and most of time death depending on amount ingested ${ }^{[10-12]}$. Thus this toxicity is dosedependent; during a clinical study, small doses did not display any side effects; the highest dose that patients could tolerate after oral ingestion was found to be $0.8 \mathrm{mg} / \mathrm{kg} / \mathrm{d}$ for $6 \mathrm{w}^{[3]}$. On the other hand, many authors have tried to counteract its toxicity by maintaining its pharmacological effect: some mixed it with selenium (its supplementation in the ration alleviated the harmful effect of the high level gossypol on most haematological parameters ${ }^{[11]}$; others have focused on suppressing

This is an open access article distributed under the terms of the Creative Commons Attribution-NonCommercial-ShareAlike 3.0 License, which allows others to remix, tweak, and build upon the work non-commercially, as long as the author is credited and the new creations are licensed under the identical terms

Accepted 29 November 2017

Revised 17 April 2017

Received 07 November 2016

Indian J Pharm Sci 2018;80(1):199-204 
the aldehyde groups, which stimulated much interest in derivatives or analogues in which these groups are changed (the toxicity of gossypol has been associated with these aldehyde groups $)^{[13,14]}$. Furthermore, gossypol gel used topically on Macaca arctoides and humans for contraceptive purpose was well accepted as no side effects were reported and inspection revealed no skin irritation ${ }^{[15,16]}$; this leads to assumption that gossypol used topically could be safer than when used orally or parenterally. Recently, in the same framework of minimizing its side effects, our laboratory produced two suitable topical formulations, first gossypol was incorporated into L-ascorbyl palmitate (L-AP) coage ${ }^{[17]}$ and second gossypol was incorporated into L-ascorbyl ibuprofenate (L-AI) coage ${ }^{[18]}$. Even if these two topical formulations have been a success, authors did not go further by making transdermal studies either ex vivo or in vivo to check whether gossypol carried by these two coagels can or not pass across the stratum corneum to the systemic circulation so that it can be used safely in future as a topical drug. Even though during the time effective medicines have emerged, at the same time some of them such as antibiotics have lost their activity due to the development of different mechanisms of antibacterial resistance, most importantly because of their misuse. Therefore, new medicines are always essential solutions to counteract this issue $\mathrm{e}^{[19,20]}$.

However, it is important to investigate the efficiency of transport using appropriate methods, preferably in ex vivo studies using porcine ears first, wellaccepted as a decent facsimile of the human skin counterpart ${ }^{[21]}$. Knowledge of the reservoir formation of topically applied drugs in the stratum corneum is important to optimize topical drug therapy, and minimize systemic side effects ${ }^{[22]}$. Tape stripping is one of techniques used for dermatopharmacokinetic studies, it is a simple and efficient method for the assessment of quality and efficacy of cosmetics and dermatological formulations ${ }^{[23-25]}$. Hence after its description by Pinkus ${ }^{[26]}$, it has become a standard method in dermatological research ${ }^{[27]}$ and a particularly useful technique to assess the local bioavailability of drugs whose target site is the stratum corneum itself (such as antifungal agents or antiseptics) ${ }^{[25]}$. The tape strips contain the amount of corneocytes and the corresponding penetrated formulation, which can afterwards be detected by classical analytical chemical method such as colorimetric method.

Ferric chloride test method is an analytical qualitative colorimetric methodology frequently used to detect phenols within other substances in solution by giving a specific colour depending on solvent used ${ }^{[28-30]}$. It is preferred as it is accepted to be simple, selective and accurate; it even detects a small concentration of target molecule ${ }^{[31]}$. The question of what reaction actually occurs when ferric chloride in a solvent gives a colour with a phenol has been discussed by many authors ${ }^{[32,33]}$. Besides, this method is used to detect salicylates in urine ${ }^{[34]}$ and cannabis resin ${ }^{[35]}$. However, along this study the gossypol penetration investigation was determined by tape stripping coupled with ferric chloride test for phenols method. L-AP and L-AI coagels containing gossypol $5 \% \mathrm{w} / \mathrm{w}$ were prepared as described previously ${ }^{[17,18]}$; a stock solution of $22 \times 10^{-3} \mathrm{M}$ of iron (III) chloride hexahydrate $\left(\mathrm{FeCl}_{3} \cdot 6 \mathrm{H}_{2} \mathrm{O}\right)$ was prepared by diluting $0.15 \mathrm{~g}$ of $\mathrm{FeCl}_{3} \cdot 6 \mathrm{H}_{2} \mathrm{O}$ (Sinopharm Chemical Reagent Co. Ltd) to $25 \mathrm{ml}$ with acetone, then stored in a refrigerator at $4^{\circ}$; different concentration series of gossypol $\left(17 \times 10^{-3}, 17 \times 10^{-4}, 17 \times 10^{-5}, 17 \times 10^{-6}\right.$, $17 \times 10^{-7}, 2 \times 10^{-8}$ and $17 \times 10^{-9} \mathrm{M}$ ) were prepared by diluting $10^{-1}, 10^{-2}, 10^{-3}, 10^{-4}, 10^{-5}, 10^{-6}$ and $10^{-7} \mathrm{~g}$ of gossypol acetic acid to $10 \mathrm{ml}$ with $7.4 \times 10^{-4} \mathrm{M}$ of $\mathrm{FeCl}_{3} \cdot 6 \mathrm{H}_{2} \mathrm{O}$ solution. About $10 \mu \mathrm{l}$ of each solution of gossypol were deposited on plate, then dried for $1 \mathrm{~min}$, the colour change has been investigated by visual observation. This experiment was conducted in triplicate. This study was performed on 14 fresh porcine ears from 7 pigs (4 males and 3 females) aged between 3 and 6 mo with left and right ears, obtained from a local abattoir, which were slaughtered on the day of the experiments; they have been treated according to the National Institutes of Health Guide for the Care and Use of Laboratory Animals ${ }^{[36]}$. Ears were rinsed with cold water and then blotted dry with soft tissue; any visible hairs were trimmed carefully with scissors. The experiments were performed on the middle of the reverse side of the ears. All subsequent manipulations and measurements were performed under ambient laboratory conditions $\left(20^{\circ}\right)$ without further treatment of the membrane (i.e., the skin remained on the isolated ear). Subjects were given code numbers 1-7. Investigations were carried out with two coagels containing $5 \% \mathrm{w} / \mathrm{w}$ of gossypol. L-AP coagel and L-AI coagel were applied on defined skin area of the 14 healthy porcine ears. Two $63 \mathrm{~cm}^{2}$ areas of application were marked on the reverse side of the right and left ears of each animal. A distance of $3 \mathrm{~cm}$ was kept away between both application areas. One coagel was applied to left ear while other was being applied to right one, $0.15 \mathrm{~g}$ of coagel has being used for each skin application, which corresponds to 
$200 \mu \mathrm{g} / \mathrm{cm}^{2}$. In fact, the coagel was drawn up in syringe and measured subsequently. The coagels were dabbed onto the marked area and distributed homogeneously afterwards with a saturated finger cot.

Adhesive tape strips (Tesafilm no 5529 Beiersdorf, Hamburg, Germany) were first marked by $4 \times 2 \mathrm{~cm}^{2}$ before applying them on marked skin area, $2 \mathrm{~h}$ for one skin area and 30 min for other marked skin area after coagel application. The strips of adhesive tapes were carefully adhered to the marked skin site to avoid folds using the uniform pressure $\left(140 \mathrm{~g} / \mathrm{cm}^{2}\right)$, with constant weight $^{[37]}$. Before applying the first tape on marked skin, we first wiped the marked area with a cotton swab soaked by distilled water in purpose to remove drug not absorbed throughout the $\operatorname{skin}^{[38]}$. Along tape stripping we weighed each single tape strip prior to application and after removal in purpose to obtain the amount of stratum corneum with or without gel using microbalance covering a weight range from $2 \mu \mathrm{g}$ to $20 \mathrm{~g}$. The strips were removed from the skin in one quick move. The tape stripping was repeated on the same skin area 22 times, but two firsts tape strips were discarded due to assumption that they are not relevant to dermatopharmacokinetic studies. Each tape was placed in sample holder (a tube of $5 \mathrm{~cm}^{3}$ ). Removed tapes were cut to a size of $4 \times 2 \mathrm{~cm}^{2}$ and kept in a sample holder; $4 \mathrm{ml}$ of acetone were added to each tube, then let rest in refrigerator $4^{\circ}$ for $2 \mathrm{~h}$. Sample holders were opened afterwards, tape strips were removed out using pliers and acetone was evaporated using an evaporator. In order to detect gossypol in each sample, $30 \mu 1$ of 7.4.10-4 $\mathrm{M}$ solution of $\mathrm{FeCl}_{3} \cdot 6 \mathrm{H}_{2} \mathrm{O}$ was added into the sample holders by gently shaking for $2 \mathrm{~min}, 10 \mu \mathrm{l}$ was withdrawn, deposited onto plate and dried for at least 2 min. The colour change has been investigated by visual observation. This technique has been applied for every single sample, coagel and porcine ear, thus 40 samples were analysed in this way for each ear. Control tests were prepared by removing successively 20 tapes from the same untreated skin area; each tape has been put in a holder and treated in the same manner as above. In preparation of positive control, $30 \mu \mathrm{l}$ of $17 \times 10^{-3} \mathrm{M}$ solution of gossypol in $22 \times 10^{-3} \mathrm{M}$ solution of $\mathrm{FeCl}_{3} \cdot 6 \mathrm{H}_{2} \mathrm{O}$ was put in each of 20 tubes for $2 \mathrm{~min}$, and then $10 \mu \mathrm{l}$ was taken from each tube and deposited on the same test plate at different areas. Negative control was prepared by putting $30 \mu 122 \times 10^{-3} \mathrm{M}$ solution of $\mathrm{FeCl}_{3} \cdot 6 \mathrm{H}_{2} \mathrm{O}$ in control test tube for $2 \mathrm{~min}$, taking $10 \mu \mathrm{l}$ from the tube and deposit on same plate. The results were statistically analysed by SPSS packet. At $95 \%$ confidence interval, $\mathrm{p}<0.05$ was accepted significant.

The gossypol identification by ferric chloride test for phenols is given in fig. 2. Normally $\mathrm{FeCl}_{3} \cdot 6 \mathrm{H}_{2} \mathrm{O}$ solution in acetone and gossypol powder is yellow each; the solution has immediately changed to black when gossypol powder was added to the solution of $\mathrm{FeCl}_{3} \cdot 6 \mathrm{H}_{2} \mathrm{O}$. In order to determine the gossypol sensitivity, $\mathrm{FeCl}_{3} \cdot 6 \mathrm{H}_{2} \mathrm{O}$ was chosen to be $22 \times 10^{-3} \mathrm{M}$, the influence of the gossypol concentration on solution of $\mathrm{FeCl}_{3} \cdot 6 \mathrm{H}_{2} \mathrm{O}$ was examined over the range of $17 \times 10^{-3} \mathrm{M}$ to $17 \times 10^{-9} \mathrm{M}$. More the concentration of gossypol decreased more the blackness of solution decreased (fig. 2A), it disappeared completely to the solutions less than $17 \times 10^{-8} \mathrm{M}$ of gossypol. Therefore, $17 \times 10^{-8} \mathrm{M}$ was selected as lowest concentration, which can be detected for the present system, and the blackness of the solution was linked to the presence of gossypol in solution ,as it is known that this colour change is likely due to the iron-phenol complex formed ${ }^{[29]}$.

In the purpose of checking whether there were no other phenols from the skin, which could be responsible of colour change, positive (fig. 2B) and negative control (fig. 2C) showed the absence of any phenol in stratum corneum from untreated skin due to respectively unchanged yellow and black colour. Therefore, the only substance responsible for solution colour change from yellowish to blackness was confirmed to be gossypol with assumption that it formed a complex with iron. Even though this method cannot be used to accurately quantify the amount of gossypol on tape strips, it is a good technique to follow its penetration through stratum corneum. Thus, gossypol penetration into stratum corneum was obtained by analysing each tape strip on each ear, tape stripping procedure was continued in the application areas of all ears, every single tape was analysed for its gossypol content from first to $20^{\text {th }}$ tape strip; after deposit of $10 \mu 1$ of test sample the colour was always checked and compared to that of controls, if it appeared to be black the test was being confirmed positive, if the yellowish colour persisted no gossypol detected. More one went from the first tape to next up to $20^{\text {th }}$, more the blackness of solution became lighter and pass to yellow (fig. 2D and E), thus the highest amount of gossypol were detected on skin surface and uppermost part of stratum corneum.

Fig. 3, the penetration profile is presented for both formulations where the gossypol detection through the 

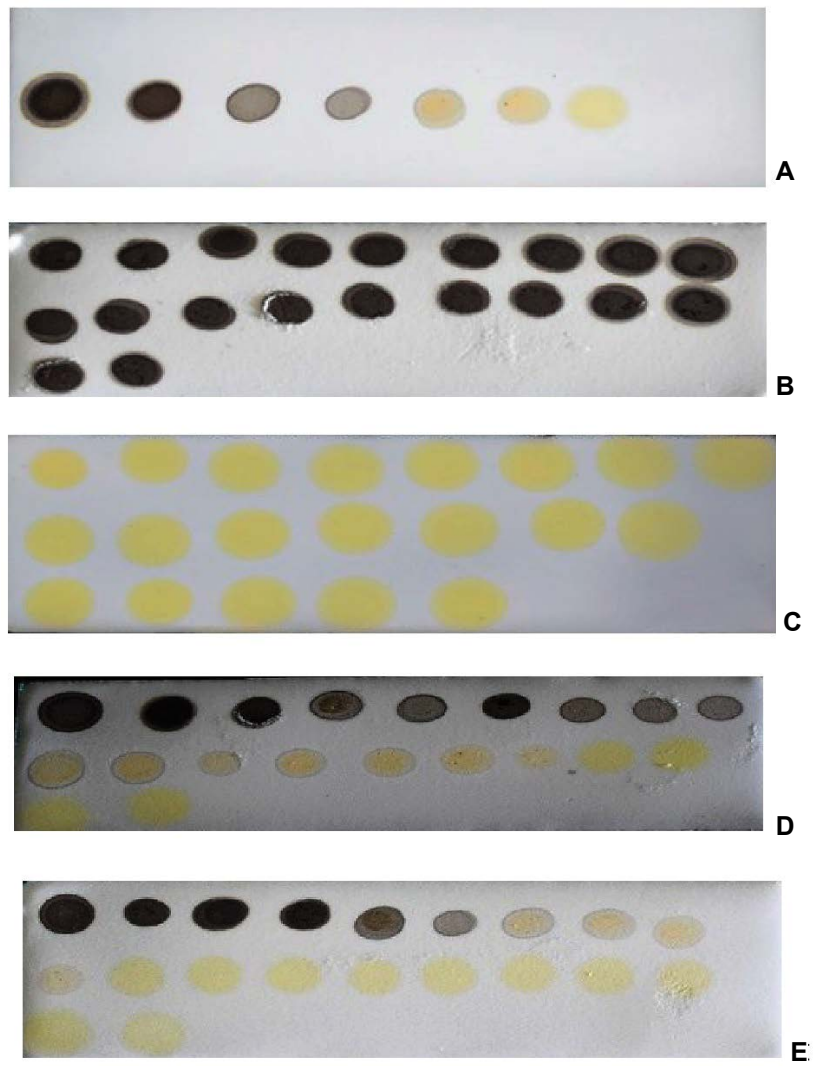

Fig. 2: Detection of gossypol in solution by ferric chloride test for phenols method

A) Color change of different concentrations of gossypol in $22 \times 10^{-3} \mathrm{M}$ solution of $\mathrm{FeCl}_{3} \cdot 6 \mathrm{H}_{2} \mathrm{O}$; B) positive control plate; $\mathrm{C}$ ) negative control plate; D) detection of gossypol in SC of Pig No. 4, after application of L-AI $2 \mathrm{~h}$; E) gossypol detection in stratum corneum of pig no. 5 after application of L-AP 2 h

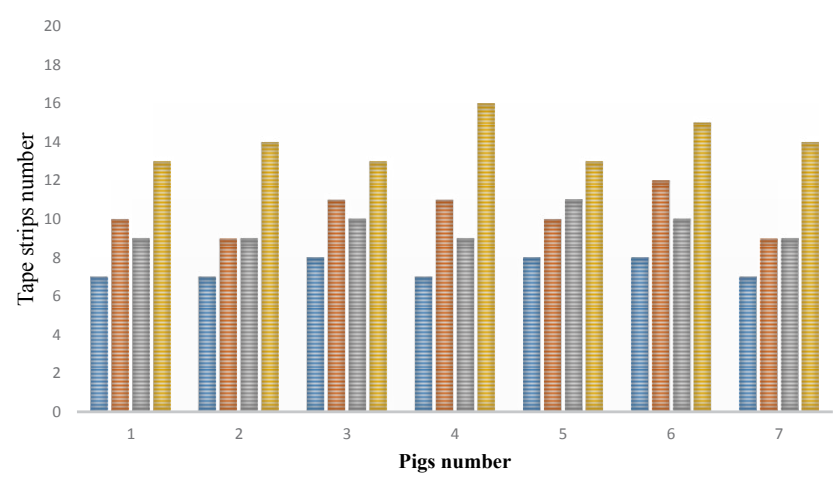

Fig. 3: Gossypol penetration through stratum corneum for both coagels

Gossypol penetration through stratum corneum for both coagels L-AP (L-ascorbyl palmitate) and L-AI (L-ascorbyl ibuprofenate) after $30 \mathrm{~min}$ and $2 \mathrm{~h}$ of skin application. $\mathrm{L}$-AP 30 min, $\approx$ L-AP 2 h, $\square$ L-AI 30 min, $\approx$ L-AI 2 h

stratum corneum is correlated with the tape numbers. The penetration profiles of gossypol are depicted by the length of colored bars in accordance with the formulation and duration of application. There is a difference of penetration within each animal, but the penetration variation of the same coagel within same period among animals appeared to be insignificant. Therefore, L-AI $2 \mathrm{~h}$ pig 4 showed the deepest penetration and L-AP pig. 1, 2, 4 and 7 the lowest. The duration of application and type of carrier influenced the penetration; this is shown in fig. 4, where the cumulative comparison of L-AP and L-AI are presented, longer is the duration of application deeper is gossypol penetration. L-AI has shown to be a better carrier of gossypol through the skin than L-AP coagel. Therefore, gossypol was generally detected on the uppermost part of stratum corneum for L-AP 30 min whereas the application using L-AI $30 \mathrm{~min}$ caused a deeper penetration; on the other hand, application after $2 \mathrm{~h}$ presented the same scenario but with deepest penetration.

Stratum corneum weighing for all samples has been carried out, the quantity removed from the first tape strip up to last one are shown in Table 1; the substances removed was generally decreasing from the first tape, but no tape strip showed to be devoid of stratum corneum even for last tapes. So, none of these two formulations has carried gossypol beyond stratum corneum, as the deepest gossypol was detected to the porcine ear 4 after $2 \mathrm{~h}$ of L-AI application on $16^{\text {th }}$ tape; from this to $20^{\text {th }}$ no gossypol was detected, but the weight tapes after removal continued to increase; that increase corresponds only to corneocytes amount as it is not possible to remove living cells from the tissue by tape stripping; then 20 tape strips have been sufficient for this study even though are not sufficient to remove a whole corny layer. In fact, the amount of removed substances was decreasing from uppermost to deeper area of skin, this is in agreement with the observation that the amount of stratum corneum removed with higher tape strip numbers is reduced because of the increased adhesion of the corneocytes.

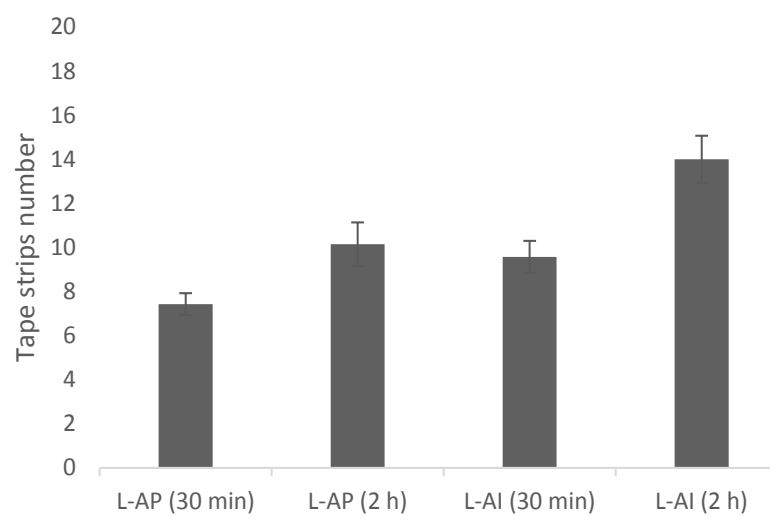

Fig. 4: Cumulative penetration of gossypol through stratum corneum

Cumulative penetration of gossypol through stratum corneum after application of L-AP (L-ascorbyl palmitate) or L-AI (L-ascorbyl ibuprofenate) coagel after $30 \mathrm{~min}$ and $2 \mathrm{~h}$ 
TABLE 1: CUMULATIVE AMOUNT OF STRATUM CORNEUM REMOVED BY EACH OF 20 TAPE STRIPS

\begin{tabular}{|c|c|c|c|c|}
\hline \multirow{2}{*}{$\begin{array}{l}\text { Tape } \\
\text { strips } \\
\text { number }\end{array}$} & \multicolumn{4}{|c|}{$\begin{array}{l}\text { Amount of stratum corneum removed from } \\
\text { the skin }\end{array}$} \\
\hline & AP (30 min) & $\mathrm{Al}(30 \mathrm{~min})$ & AP $(2 h)$ & $\mathrm{Al}(2 \mathrm{~h})$ \\
\hline 1 & $25 \pm 1.2$ & $26 \pm 2.1$ & $27 \pm 2$ & $28 \pm 2.3$ \\
\hline 2 & $24 \pm 1$ & $24 \pm 1.4$ & $26 \pm 1.9$ & $26 \pm 2$ \\
\hline 3 & $22 \pm 0.8$ & $24 \pm 1.1$ & $24 \pm 1.4$ & $23 \pm 1.5$ \\
\hline 4 & $20 \pm 0.8$ & $22 \pm 0.9$ & $23 \pm 1$ & $23 \pm 1.1$ \\
\hline 5 & $20 \pm 0.30$ & $20 \pm 0.5$ & $21 \pm 0.8$ & $22 \pm 0.9$ \\
\hline 6 & $18 \pm 0.23$ & $19 \pm 0.30$ & $19 \pm 0.77$ & $19 \pm 0.67$ \\
\hline 7 & $18 \pm 0.27$ & $18 \pm 0.27$ & $20 \pm 0.23$ & $21 \pm 0.23$ \\
\hline 8 & $15 \pm 0.17$ & $16 \pm 0.19$ & $17 \pm 0.12$ & $18 \pm 0.11$ \\
\hline 9 & $13 \pm 0.32$ & $14 \pm 0.26$ & $15 \pm 0.09$ & $16 \pm 0.23$ \\
\hline 10 & $13 \pm 0.44$ & $13 \pm 0.30$ & $14 \pm 0.23$ & $14 \pm 0.21$ \\
\hline 11 & $11 \pm 0.22$ & $12 \pm 0.18$ & $13 \pm 0.12$ & $14 \pm 0.12$ \\
\hline 12 & $9 \pm 0.14$ & $10 \pm 0.15$ & $13 \pm 0.32$ & $12 \pm 0.09$ \\
\hline 13 & $7 \pm 0.23$ & $8 \pm 0.12$ & $10 \pm 0.09$ & $10 \pm 0.10$ \\
\hline 14 & $6 \pm 0.09$ & $7 \pm 0.14$ & $8 \pm 0.16$ & $8 \pm 0.14$ \\
\hline 15 & $6 \pm 0.10$ & $6 \pm 0.08$ & $7 \pm 0.22$ & $8 \pm 0.21$ \\
\hline 16 & $5 \pm 0.16$ & $5 \pm 0.05$ & $7 \pm 0.31$ & $7 \pm 0.08$ \\
\hline 17 & $5 \pm 0.00$ & $5 \pm 0.03$ & $5 \pm 0.05$ & $6 \pm 0.02$ \\
\hline 18 & $4 \pm 0.21$ & $4 \pm 0.09$ & $4 \pm 0.09$ & $4 \pm 0.12$ \\
\hline 19 & $4 \pm 0.05$ & $4 \pm 0.10$ & $4 \pm 0.30$ & $4 \pm 0.22$ \\
\hline 20 & $4 \pm 0.33$ & $4 \pm 0.12$ & $4 \pm 0.33$ & $4 \pm 0.03$ \\
\hline
\end{tabular}

L-Al $30 \mathrm{~min}$, application of L-ascorbyl ibuprofenate coagel containing $5 \% \mathrm{w} / \mathrm{w}$ of gossypol for $30 \mathrm{~min}$; L-Al $2 \mathrm{~h}$, application of L-ascorbyl ibuprofenate coagel containing $5 \% \mathrm{w} / \mathrm{w}$ of gossypol and for $2 \mathrm{~h}$; L-AP $30 \mathrm{~min}$, application of L-ascorbyl palmitate coagel containing $5 \% \mathrm{w} / \mathrm{w}$ of gossypol for $30 \mathrm{~min}$; L-AP $2 \mathrm{~h}$, application of L-ascorbyl palmitate coagel containing $5 \% \mathrm{w} / \mathrm{w}$ of gossypol for $2 \mathrm{~h}$; the amount values of stratum corneum are given in $10^{-4} \mathrm{~g}$; data are given as mean $\pm S D$

However, topical use of gossypol will be preferred to its systemic use due to its toxicity. This systemic toxicity will be avoided if and only if gossypol stays at the level of stratum corneum, for both of gossypolcontaining coagels used along this study none has carried gossypol beyond stratum corneum even if L-AI coagel has shown to carry it deeper than L-AP did (fig. 4), thus it stayed entrapped into stratum corneum. In addition, the type of formulation can influence the penetration of substance, as both formulations contain the same concentration of drug, the absolute amount of drug permeating the skin strongly dependent upon the vehicle in which the active drug is applied.

The penetration of substance cannot be only influenced by its vehicle but many other factors are at stake regarding the physicochemical property of the substance itself like lipid solubility, size, degree of ionization, and the area of absorptive surface; because the cell membrane and intercellular lipid domains of the stratum corneum are lipoid, lipid-soluble drugs diffuse most rapidly, small molecules (with molar weight less than $500 \mathrm{Da}$ ) tend to penetrate membranes more rapidly than larger ones, gossypol with $518.55 \mathrm{Da}$ molecular weight is supposed to penetrate poorly, this explain the reason why it stayed distributed on uppermost of stratum corneum and never reach the living cells (figs. 3 and 4). In addition, a numerous physiological factors can affect the skin barrier and hence skin permeability; it is important to recognize that the skin structure changes as the skin ages, environmental factors such as exposure to solar radiation and chemicals, including cosmetics and soaps, influence skin structure and function over time. Furthermore, ethnicity, gender and skin area can influence the drug penetration through the stratum corneum, these explain the reason why each ear presented its own penetration profile (fig. 3). Moreover, gossypol carried by L-AI and L-AP coagels can be used as other drugs whose target is stratum corneum itself, such as antifungal and antiseptic agents against some skin-associated bacteria like $S$. epidermidis, where the pathogen resides on or within the outermost layer of the skin; the drug must be delivered to the stratum corneum in adequate concentrations to inhibit the growth of the pathogen. But our ex vivo results need to be confirmed by following in vivo and clinical studies.

\section{Acknowledgments:}

The authors acknowledge the support from the School of Pharmaceutical Sciences and School of International students, Jiangnan University (China).

\section{Conflict of interest:}

The authors of this article declare no conflict of interest in this study.

\section{Financial support and sponsorship:}

Nil.

\section{REFERENCES}

1. Keshmiri-Neghab H, Goliaei B. Therapeutic potential of gossypol: an overview. Pharm Biol 2014;52:124-8.

2. Markman L, Greenberg D. Gossypol Derivatives. Washington DC, US; Department of Agriculture and the National Science Foundation; 1968.

3. Wang X, Howell CP, Chen F, Yin J, Jiang Y. Gossypol-a polyphenolic compound from cotton plant. Adv Food Nutr Res 2009;58:215-63.

4. Margalith P. Inhibitory effect of gossypol on microorganisms. Appl Microb 1967;15:952.

5. Lin TS, Schinazi, R. Griffith B, August E, Eriksson B, Zheng $\mathrm{D}$, et al. Selective inhibition of human immunodeficiency 
virus type 1 replication by the (-) but not the $(+)$ enantiomer of gossypol. Antimicrob Agents Chemother 1989;33:2149-51.

6. Tai-Shun L, Schinazi RF, Zhu J, Birks E, Carbone R, Yikang S, et al. Anti-HIV-1 activity and cellular pharmacology of various analogues of gossypol. Biochem Pharmacol 1993;46:251-5.

7. Baram N, Biktimirov L, Ziyaev KL, Paizieva R, Ismailov A. Antiviral and interferon-inducing activities of gossypol and its derivatives. Chem Nat Comp 1995;31:299-303.

8. Dorsett PH, Kerstine EE, Powers LJ. Antiviral activity of gossypol and apogossypol. J Pharm Sci 1975;64:1073-5.

9. Radloff RJ, Deck LM, Royer RE, Vander Jagt DL. Antiviral activities of gossypol and its derivatives against herpes simplex virus type II. Pharmacol Res Commun 1986;18:1063-73.

10. Eagle E. A review of some physiological effects of gossypol and cottonseed pigment glands. J Am Oil Chem Soc 1960;37:40-3.

11. El-Mokadem M, Taha T, Samak M, Yassen A. Counteracting the hematological toxicity of gossypol by using selenium supplementation in rams. Small Ruminant Res 2013;114:86-9.

12. El-Nockrashy A, Lyman C, Dollahite J. The acute oral toxicity of cottonseed pigment glands and intraglandular pigments. $\mathrm{J}$ Am Oil Chem Soc 1963;40:14-7.

13. Royer RE, Deck LM, Vander Jagt TJ, Martinez FJ, Mills RG, Young SA, et al. Synthesis and anti-HIV activity of 1,1'-dideoxygossypol and related compounds. J Med Chem 1995;38:2427-32.

14. Krempl C, Hanna MH, Guillermo HJ, Michael R, Riya $\mathrm{CM}$, Wilhelm B, et al. Gossypol toxicity and detoxification in Helicoverpa armigera and Heliothis virescens. Insect Biochem Mol Biol 2016;78:69-77.

15. Cameron SM, Waller DP, Zaneveld L. Vaginal spermicidal activity of gossypol in the Macaca arctoides. Fertil Steril 1982;37:273-4.

16. Ratsula K, Maija H, Karri W, Tapani L. Vaginal contraception with gossypol: a clinical study. Contraception 1983;27:571-6.

17. Okoampah A, Tang L. The effect of incorporating gossypol into L-ascorbyl palmitate coagel on rheological and viscoelastic properties. Lat Am J Pharm 2015;34:576-84.

18. Wan Q, Tang L. Coagel from L-ascorbyl ibuprofenate: properties, characterization and application. Lat Am J Pharm 2015;34:1664-71.

19. Atkinson BA, Lorian V. Antimicrobial agent susceptibility patterns of bacteria in hospitals from 1971 to 1982 . J Clin Microbiol 1984;20:791-6.

20. Redo M, Rios J and Villar A. A review of some antimicrobial compounds isolated from medicinal plants reported in the literature 1978-1988. Phytother Res 1989;3:117-25.

21. Herkenne C, Naik A, Kalia YN, Hadgraft J, Guy RH. Pig ear skin ex vivo as a model for in vivo dermatopharmacokinetic studies in man. Pharm Res 2006;23:1850-6.

22. Turpeinen M. Absorption of hydrocortisone from the skin reservoir in atopic dermatitis. $\mathrm{Br} \mathrm{J}$ Dermatol 1991;124(4):358-60.

23. Lademann J, Jacobi U, Surber C, Weigmann HJ, Fluhr JW. The tape stripping procedure-evaluation of some critical parameters. Eur J Pharm Biopharm 2009;72:317-23.

24. https://www.fda.gov/ohrms/dockets/ac/00/backgrd/3661b1c. pdf.

25. Herkenne C, Alberti I, Naik A,Yogeshvar NK, Mathy FX, Véronique $\mathrm{P}$, et al. In vivo methods for the assessment of topical drug bioavailability. Pharm Res 2008;25:87.

26. Pinkus H. Examination of the epidermis by the strip method of removing horny layers: I. Observations on thickness of the horny layer, and on mitotic activity after stripping. J Invest Dermatol 1951;16:383-6.

27. Bronaugh R, Maibach H. Percutaneous absorption drugcosmetics-mechanism-methodology. J Appl Cosmetol 1999; 17:116-9.

28. Murphy CR, Thackberry SP, Boehm RE. Process for removal of phenols from dilute aqueous solutions thereof. US Patent No: US 4196305 A; 1980.

29. Soloway S, Wilen S. Improved ferric chloride test for phenols. Anal Chem 1952;24:979-83.

30. Hasegawa T, Usui T. Cautionary note regarding the phenol color test by ferric chloride in acidic solution. J Chem Educ 1992;69:840.

31. Xu Y, Sun Y, Zhang Y, Lu C, Miao J. Detection of biological thiols based on a colorimetric method. J Zhejiang Univ-Sc B 2016;17:807.

32. Banerjee S, Haldar BC, Constitution of Ferri-Phenol Complex in Solution. Nature 1950;165:1012.

33. Gore P, Newman P. Quantitative aspects of the colour reaction between Iron (III) and phenols. Analytica Chimica Acta 1964;31:111-20.

34. Broder JN. The ferric chloride screening test. Ann Emerg Med 1987;16:1188.

35. Grlić L, Tomić N. Examination of cannabis resin by means of ferric chloride test. Experientia 1963;19:267-8.

36. https:/grants.nih.gov/grants/olaw/guide-for-the-care-anduse-of-laboratory-animals.pdf.

37. Tassopoulos T, Maeder S, Imandis G, Figueiredo V, Smith EW, Surber C. The Essential Stratum Corneum. Boca Raton, Florida: CRC Press; 2002. p. 175-8.

38. Shah VP, Flynn GL, Yacobi A, Maibach HI, Bon C, Fleischer $\mathrm{NM}$, et al. Bioequivalence of topical dermatological dosage forms-methods of evaluation of bioequivalence. Pharm Res 1998;15(2):167-71. 